Lingua e Literatura, n. 21, p. 131-143, 1994/1995.

\title{
A CONSTRUÇÃO DO SENTIDO NA CANÇÃO POPULAR
}

\author{
Luiz Tatit*
}

RESUMO: A partir das estreitas interações semióticas entre canção e fala cotidiana esse trabalho visa contribuir para o reconhecimento de um lugar teórico onde os valores essenciais, que circulam pelas melodias e pelas letras das canções brasileiras, se encontram compatibilizados. Trazendo o processo sintagmático e as categorias temporais para o centro da reflexão, o esforço aqui empreendido tem ainda como meta conceber uma base metodológica homogênea para o desvendamento das leis que engendram as continuidades $e$ as descontinuidades retratadas tanto nas letras como nas melodias das canções.

Palavras-chave: continuidade, descontinuidade, andamento, melodia, letra.

"Si la musique savante est bien un langage artificiel et construit, que dire du chant populaire qui, tout en possédant les mêmes principes fondamentaux d'organization sémiotique, paraît néanmoins naturel?"

\section{(A. J. Greimas et J. Courtés)}

A canção popular é produzida na intersecção da música com a língua natural. Valendo-se de leis musicais para sua estabilização sonora, a canção não pode, de outra parte, prescindir do modo de produção da linguagem oral. Daí a sensação de que um pouco de cada nova obra já existia no imaginário do povo, senão como mensagem final ao menos como maneira de dizer. Estudar a canção é no fundo

(*) Professor da Universidade de São Paulo.

(1) A semiótica "natural" compreende as duas macrossemióticas (mundo natural e língua natural) imanentes às atividades produtivas dos falantes. Embora sejam constantemente manipulados $\mathrm{e}$ reconstruidos pelas práticas sociais cotidianas, esses vastos conjuntos significantes transcendem o indivíduo, não podendo, portanto, sofrer modificações neste plano. Cf. A. J. Greimas et J. Courtés Sémiotique. Dictionnaire Raisonné de la Théorie du Langage, Paris, Hachette, 1979, pp. 205, 250). 

p. 131-143, 1994/1995.

aceitar o desafio de explorar essa área nebulosa em que as linguagens não são nem totalmente "naturais" (no sentido semiótico do termo'), nem totalmente "artificiais" e precisam das duas esferas de atuação para construir o seu sentido.

A questão que propomos nesta oportunidade pode ser assim resumida: como criar parâmetros semióticos para abordar esse lugar híbrido de manifestação das canções? Tais parâmetros deverão ainda fornecer critérios homogêneos para uma análise integrada da letra e da melodia. Em termos pouco mais abstratos, esse trabalho corresponde a uma busca de equivalência entre sintaxe e ritmo, condição necessária para se depreender as compatibilidades entre as duas faces da canção.

\section{Interinidade Oral}

O modo de produção da linguagem oral pode ser compreendido à luz da famosa oposição saussure-hjelmsleviana entre forma e substância. Nossas falas produzem substância (ou matéria) sonora para carrear um conteúdo que, na verdade, só se define num plano categorial e abstrato, onde se verificam oposições e interações sintáxicas entre unidades de diversas dimensões (fonológica, morfológica, frasal e discursiva), sem qualquer vínculo mais duradouro com seu suporte material. Esta substância de expressão é tão necessária à comunicação quanto descartável no âmbito da significação. Uma comunicação bem sucedida pode inclusive ser calculada pela rapidez com que se despreza o invólucro sonoro. ${ }^{2}$

A ênfase depositada nos aspectos intelectivos e funcionais da linguagem oral acaba por definir sua fisionomia de manifestação: estabilidade lingüísticogramatical e instabilidade sonora expressa na ausência de tratamento fonético (dispensa-se qualquer aliteração) e na imprecisão musical das curvas entoativas. De fato, a linguagem oral realiza as funções imanentes de uma língua natural que se caracterizam justamente por assegurar a intercompreensão dos falantes. Essa dimensão social e "natural" da língua atrela suas manifestações a um projeto geral de construção de consenso comunitário que prescinde da conservação sonora dos atos individuais. Daí o caráter apenas ancilar da entonação lingüística que sublinha aqui e ali alguns pontos estratégicos do texto sem se configurar como processo autônomo (ao menos no âmbito da comunicação normal do dia-a-dia). Tal imprecisão melódica é compatível com sua função interina na linguagem oral: quanto menos atrair para si a atenção do falante mais contribui para a clareza final do discurso lingüístico.

Importante considerar, de acordo com os propósitos deste trabalho, não tanto o sucesso comunicativo da linguagem oral mas sim, como já dissemos, o seu

(2) Cf. P. Valéry Variedades. São Paulo, Iluminuras, 1991, pp. 208-209. 
modo de produção. $O$ encontro da estabilidade (gramatical) lingüistica com a instabilidade (musical) entoativa, independentemente do conteúdo veiculado, incita de imediato nossa vasta experiência com a linguagem oral provocando um efeito inevitável de "realidade" enunciativa: alguém diz alguma coisa aqui e agora. A presença deste efeito, com maior ou menor intensidade, em toda e qualquer canção popular, garante a essa linguagem um grau extraordinário de aproximação às práticas "naturais" A própria credibilidade enunciativa implicada nas execuções vocais depende do êxito da apreensão simultânea do modo de produção da linguagem oral em seu interior.

Sabemos que não há nada mais gratificante ao ouvinte que sentir que o intérprete de uma canção disse tudo. Mais que isso, que ele "disse realmente" durante o tempo de interpretação. Que ele não era um ator mas o sujeito real de todos os sentimentos, eufóricos ou disfóricos, transmitidos por sua emissão vocal. Quem ouve sabe que as emoções ou os conteúdos registrados naquela emissão foram criados num tempo passado, no entanto, a presença física da voz sustenta a crença de que tudo está sendo fielmente reproduzido ou, melhor, passado a limpo durante a interpretação. Quem canta sabe que se não recuperar os conteúdos virtualizados na composição, durante o período da execução, deixando transparecer uma inegável cumplicidade com o que está dizendo (o texto) e com a maneira de dizer (a melodia), simplesmente inutiliza o seu trabalho e se desconecta do ouvinte.

Não há canção sem impressão enunciativa, sem a sensação de que o quê está sendo dito está sendo dito de maneira envolvida. Por isso, o reconhecimento dos cantores e de seus estilos é, por si só, um fator de credibilidade e confiança.

\section{Perenidade estética}

Mas nem só de impressão enunciativa alimenta-se a canção. A presença interina da sonoridade na linguagem oral é até certo ponto incompatível com a intenção de perenidade que caracteriza uma obra estética. A forma fonológica da expressão lingüística e mesmo as leis elementares de ordenação entoativa (baseadas nas variações da ascendência e da descendência) nunca foram suficientes nem adequadas à estabilização do componente melódico da canção. Se a função estética depende sempre dos processos de conservação da matéria, não podemos deixar de considerar uma outra forma que incida diretamente sobre a substância de expressão sonora, regulando sua manifestação concreta. Trata-se aqui, evidentemente, da forma musical. Por meio de leis de recorrência, de alternância, de gradação, entre outras, a música fornece os recursos conhecidos para a estabilização das alturas, das unidades rítmicas, dos contornos monofônicos e polifônicos, da base harmônica, enfim, de todos os elementos desprezados nas manifestações da linguagem oral. 
Mantendo aspectos do modo de produção oral, com seus efeitos de naturalidade e presentificação enunciativa, e assimilando, simultaneamente, as formas de conservação sonora da linguagem musical, a canção desempenha um papel cultural privilegiado na medida em que promove continuamente a perenização do instante enunciativo. Ela necessita das duas instâncias de apreensão para construir o seu sentido.

Ora, a musicalização da fala corresponde a um processo de ritualização de uma sonoridade que, a princípio, teria função totalmente passageira. Ao adquirir leis próprias de funcionamento, que se manifestam sobretudo na ordenação melódica, a canção impõe uma desaceleração às manifestações lingüístico-entoativas retirando um pouco de sua intervenção ligeira e descontínua. No mesmo ato, deposita, ao lado das oposições intelectivas, as emoções contínuas que só a melodia pode trazer.

\section{Andamento: som e ruído}

Surge, assim, a primeira possibilidade de semiotização das atividades, oral e musical, que fundam genericamente a canção. Se a presença da fala é marca de rapidez, imediatismo e eficácia do instante enunciativo e, por outro lado, a presença da música significa estabilização da matéria sonora, ritualização e conservação estética, podemos instituir a categoria andamento como parâmetro temporal de análise e dela depreender uma tensão entre aceleração e desaceleração respondendo, respectivamente, pelos valores descontínuos e pelos valores contínuos.

$O$ centro das questões aqui debatidas está no pensamento de P. Valéry que contrapõe as funções utilitárias da "fala" do "andar", e da "prosa" às funções estéticas do "canto", da "dança" e da "poesia" ${ }^{3}$ Se identificarmos as primeiras com a categoria da interinidade e as últimas com a da perenidade, já podemos considerar a presença dos primeiros sinais de celeridade no caráter efêmero das expressões que conduzem as funções utilitárias em oposição aos sinais de duração dos processos estéticos que pretendem conservar a matéria (sonora, gestual ou gráfica).

A opção estética de conservação da matéria sonora reflete um primeiro compromisso com a duração, ou seja, com a estabilização dos processos fônicos mas, ao mesmo tempo, não pode prescindir inteiramente dos fenômenos de instabilidade sonora que funcionam, na obra, como desvios repentinos e inesperados, como pontos de celeridade responsáveis pela dinâmica da música. O esforço dos compositores em controlar tais instabilidades e assegurar a coerência interna da peça re-

(3) Cf. P. Valéry Oeuvres. Tome I, Paris, Gallimard/La Pléiade, 1957, p. 1449. 
percute, por exemplo, nas operações tonais de preparação e resolução das dissonâncias que constituem, em última instância, recursos de desaceleração.

Trabalhos recentes na área musical vêm operando com noções que podem ser, em última instância, identificadas com o parâmetro andamento na acepção ora adotada. Destacamos a oposição som / ruído tratada sucessivamente por J. Attali e J. M. Wisnik. ${ }^{4} \mathrm{O}$ som musical, para esses autores, é um produto selecionado e depurado para atender as necessidades auditivas das mais diferentes culturas do planeta. Todas elas precisam denegar um universo ruidoso bem mais amplo para poder extrair a sonoridade que de fato representa sua ordem social e cultural. Attali chega a afirmar que a música executa, em cada comunidade, um ritual de sacrifício canalizando o ruído através de leis de ordenação. De acordo com sua visão narrativa e polemológica o ruído é um representante das forças antagonistas contra as quais a música se investe exibindo suas formas de ordenação e integração. De qualquer modo, por mais que os músicos rejeitem a ameaça contida no conceito de ruído, esta acaba retornando no decorrer de sua produção em forma de descontinuidades a serem ultrapassadas. Munida de suas forças coesivas, a música tende sempre a reconstituir os elos de continuidade renovando a cada obra os laços que ligam o sujeito aos seus valores culturais.

Wisnik aprofunda o enfoque narrativo de Attali revelando alguns princípios temporais que estão na base da oposição continuidade (assumida pelo programa do sujeito)/vs/ descontinuidade (assumida pelo anti-sujeito). Embora não mencione explicitamente a categoria do andamento como princípio geral de sua abordagem, Wisnik emprega diversas vezes o termo aceleração para definir a "turbulência" do mundo ruidoso em oposição aos estados duráveis e "constantes" criados pelo som musical. Tudo ocorre como se a música respondesse às intervenções antagonistas com o rito, a solenidade, a periodicidade, a ordenação, enfim, com todos os recursos que reafirmam as expectativas sociais e, conseqüentemente, a integração do sujeito com seus valores. Depreende-se do texto de $O$ som e o sentido que a aceleração imposta pelo ruído constitui um verdadeiro atentado contra a espera pacientemente construída pelo som.

Ora, a espera consiste numa desaceleração das etapas temporais em nome de uma previsibilidade de percurso narrativo. $O$ ruído provoca rupturas no programa do sujeito exigindo condutas de salto repentino que aceleram bruscamente $o$ percurso. Nesse sentido, ruído equivale a descontinuidade e produz, no plano do sujeito, uma sensação disfórica, ou seja, de interrupção do fluxo fórico. $O$ som, por sua vez, corresponde à retomada da continuidade e à produção subjetiva da sensa-

(4) Cf. J. Attali Bruit. Paris, PUF, 1977 e J. M. Wisnik O som e o sentido. São Paulo, Com-panhia das Letras, 1989. 

p. 131-143, 1994/1995.

ção eufórica (reintegração ao fluxo). ${ }^{5}$ Wisnik examina a assimilação desses conflitos na história "das músicas" articulando a categoria do tom em consonância/ dissonância e a categoria do pulso em fase/defasagem. Desde o período conhecido como modalismo até a fase contemporânea das simultaneidades sonoras, o que impera é a necessidade de contenção da velocidade imposta pela penetração dos ruídos (o que é considerado som numa cultura pode ser ruído em outra) que se tornam, ao longo da história, cada vez mais presentes. Daí a adoção de hábitos musicais ou verdadeiras gramáticas (modalismo, tonalismo, dodecafonismo, etc.) para ritualizar de algum modo as produções sonoras da cultura.

Evidente que não se trata apenas de produzir recursos para afastar o ruído indesejável mas, pelo contrário, também faz parte da atividade criadora de todas as épocas a incorporação dos elementos originalmente refratários ao sistema. Em vez de praticar a simples rejeição do ruído, grande parte dos músicos sempre se aplicou em sua administração (por meio de preparações e resoluções gradativas) no interior das peças, a fim de evitar também uma desaceleração excessiva. Nessa linha de verificação, Wisnik analisa a assimilação do trítono na música européia, a troca de influências sobretudo entre Europa (universo do tom) e África (universo do pulso), o sincretismo das duas tendências na música popular norteamericana, a condensação refinada da sonoridade que deu origem à gramática da canção e, por fim, as novas técnicas de ordenação e reprodução de previsibilidade generalizadas pelo avanço eletrônico e pelas necessidades de padronização do mercado cultural. Tudo isso retrata os esforços de absorção do ruído como condição para o encontro do andamento ideal das criações musicais nas diversas culturas em cada época. Se a aceleração é mais acentuada nos períodos de inovação estética, a desaceleração é típica das fases de consolidação de um sistema musical. Mas a questão do confronto e da convivência do som com o ruído constitui um desafio inerente às obras musicais de todas as épocas e de todos os povos.

\section{Tempo: descontinuidade e continuidade}

No universo da canção popular, as instabilidades entoativas, as imprecisões rítmicas, enfim a presença da fala no canto é a maior fonte de ruído que, se por um lado repugna aos cancionistas, por outro, os atrai. Afinal, como já vimos, o modo

(5) A foria representa a dimensão contínua (e hipotética) do sentido anterior à intervenção enunciativa do sujeito. Em outras palavras, ela constitui o próprio sujeito enquanto elemento "uno" integrado plenamente ao objeto. A fratura desta unidade corresponde ao primeiro ato disfórico que instaura o processo narrativo (a necessidade de recuperação do elo eufórico). Por conter em si a noção de "transporte" (phoros) esse conceito atribui ao sujeito um estatuto temporal. 
de produção oral, por ser signo de presentificação enunciativa, apresenta alto rendimento semântico no momento da execução do cantor. Como a sonoridade tem vida breve na linguagem oral, a composição acaba exibindo um dom especial de perenizar (atribuir uma duração) o que parecia quase incorpóreo. E quanto mais deixa transparecer os ruídos da fala na superfície da manifestação mais assume o risco de ver a sonoridade se dissipando na clareza do texto lingüístico. Entretanto, ao controlar a velocidade da voz que fala, atribuindo-lhe uma duração no interior da voz que canta, o cancionista revela o que R. Barthes denominou "grão da voz", ${ }^{6}$ ou seja, a exata intersecção entre língua e música: a condição ideal para o efeito de verdade da obra.

A necessidade estética de estabilização do plano da expressão reforça algo que já se configura como tendência teórica na descrição do plano do conteúdo: a expansão do texto na dimensão sintagmática. A coerência do texto melódico só pode ser devidamente conferida na descrição dos acidentes locais tendo em vista os propósitos da extensão geral da obra. Nesses termos, retomamos aqui, com as devidas readaptações, a oposição intenso/extenso prevista pela Glossemática, ${ }^{7}$ definindo a ordem extensa como um nível profundo que fundamenta a análise das variações intensas. Tais variações respondem pelos fenômenos de descontinuidade sonora que tendem a ser incorporados por planos de continuidade mais profundos, pressupondo, com isso, que todo texto visa, em última instância, restabelecer um elo entre sujeito da enunciação e objeto de valor e que este elo é contínuo. Os estudos semióticos do Conteúdo fazem ressoar essas hipóteses em todos os estratos gerativos quando integra a heterogeneidade dos semas nas iterações isotópicas, quando investiga as relações polêmicas entre sujeito e anti-sujeito sob o enfoque das relações contratuais entre destinador e destinatário ou ainda quando compara as modalidades do /saber/e do /crer/e acusa a tendência da primeira em consumir o objeto ao lado da tendência da segunda em preservá-lo. ${ }^{8}$

Tudo isso indica que descontinuidade e continuidade são noções mais profundas, mais abstratas, que não podem permanecer restritas às manifestações temporais e aspectuais da superfície do discurso. Autores como H. Parret e, sobretudo, C. Zilberberg vêm propondo uma verdadeira inversão do percurso gerativo -inversão esta só parcialmente reconhecida pela semiótica padrão-, de onde se depreende uma noção de continuidade fundamental, uma espécie de junção plena, cujo sentido só se configura a partir da primeira descontinuidade. Esse fluxo -a foria- é um limite ontológico e, ao mesmo tempo, uma categoria para se compreender as ten-

(6) "Le grain de la voix" In: Musique en jeu. Paris, Seuil, nov. de 1972, n. 9.

(7) Cf. entrada "extense/intense" In: A. J. Greimas et J. Courtés Sémiotique. Dictionnaire Raisonné de la Théorie du Langage II. Paris, Hachette, 1986, p. 82.

(8) Cf. C. Zilberberg Raison et poétique du sens. Paris, PUF, 1988, p. 110. 

p. 131-143, 1994/1995.

sões que impelem o sujeito em direção ao objeto. A protensividade do sujeito e a atratividade exercida pelo objeto decorreriam, como já deixamos entender, de uma cisão primordial que instaura o objetivo último de recuperação do fluxo. E o sentido stricto sensu não seria outra coisa senão a direção assumida pelo sujeito no intuito de reencontrar o objeto.?

Um enfoque assim concebido traz implicações imediatas aos estudos semióticos. De um lado, do ponto de vista semântico, instaura o universo passional do sujeito como um lugar teórico privilegiado para a investigação. De outro, do ponto de vista sintáxico, concebe um tempo profundo -equivalente à foria ou à continuidade plena- como responsável primeiro pelas relações entre actantes no plano do conteúdo e pelas relações entre elementos sonoros no plano da expressão.

Se nossos discursos do dia-a-dia exercitam, com suas operações abstratas de conteúdo, a recomposição da continuidade temporal ou, ainda, do sentido que conduz ao objeto, a emoção estética, por sua natureza sensorial, exige que este sentido seja concretizado nos contornos do plano de expressão, como se a perenização da matéria realizasse, num lapso, a continuidade primordial e, com ela, a junção plena.

Trata-se aqui de examinar a possibilidade de constituição de um nível profundo, comum à Expressão e ao Conteúdo, considerando que as noções de descontinuidade e continuidade refletem, respectivamente, um modo intenso e um modo extenso de articulação do tempo original. Em outras palavras, antes de assumir os valores socioculturais, o sujeito semiótico seleciona os valores temporais, fazendo predominar ora as continuidades (euforias), ora as descontinuidades (disforias). ${ }^{10}$

Retomamos assim, mais uma vez, a reflexão sobre os valores descontínuos e contínuos. Os primeiros revelam uma tendência do texto para os seus componentes locais, intensos, onde a passagem de um estado a outro se processa de forma brusca e inesperada. Essa excessiva concentração do tempo no discurso pode ser avaliada também com o aumento de velocidade. É quando aparece a surpresa como efeito de sentido predominante. A escolha dos valores contínuos justifica a tendência do texto

(9) Esse tema é largamente tratado por Greimas e J. Fontanille em sua "Epistémologie des passions" In: Sémiotique des passions - des états de choses aux états d'âme. Paris, Seuil, 1991

(10) Para a semiótica não há percepção de conteúdos semânticos (biológicos, sociais, psicológicos, etc.) sem envolvimento afetivo do sujeito. Nâo há análise de conteúdo que não implique um sentimento anterior como primeiro critério de categorização: fatos que nos atraem, nos repelem ou nos causam indiferença. Alguns modelos recentes já incorporados no segundo volume do Dicionário de Semiótica (Op. Cit.) chegam a propor que, antes de nos engajarmos com os conteúdos culturais, escolhemos os valores fóricos, continuos (eufóricos) ou descontínuos (disfóricos), que nos servirão de parâmetro para a seleção posterior dos objetos. 
para a dimensão extensa, para a recuperação das etapas intermediárias (as passagens gradativas), numa palavra, para a desaceleração do tempo e reconstituição da duração. É quando surge a espera como efeito de sentido predominante.

Nesses termos, estamos propensos a homologar essa noção de tempo profundo com a de andamento, este um conceito de origem musical mas com articulação (aceleração/desaceleração) compatível tanto com o plano da expressão, como com o plano do conteúdo.

\section{Canção: aceleração e desaceleração}

Em função do conteúdo estudado até aqui, podemos propor um exame geral dos diversos processos de composição e interpretação na canção brasileira. Há cancionistas que produzem no limite da instabilidade sonora da fala (ex. Jorge Ben Jor), enquanto outros se caracterizam por atribuir estabilidade e coerência musical a todas as sugestões melódicas de base entoativa (ex: Tom Jobim). Entre esses extremos, inúmeras canções apresentam, internamente, a alternância desses comportamentos de estabilidade e instabilidade sonoras (Caetano Veloso vem experimentando esses limiares em seus últimos trabalhos -cf. Estrangeiro, Fora de Ordem, Circuladô, etc).

No plano da interpretação, há que se mencionar especialmente a aventura recente de João Gilberto cuja característica mais notável está em retirar os pontos de referência, as balizas rítmicas que estruturam as canções consagradas do repertório popular e chegar ao limite da instabilidade, onde a obra ainda pode ser identificada mas nem sempre reconhecida. Basta compararmos, como exemplo, a versão de Caetano para Sampa com a versão de João Gilberto.

O mesmo parâmetro temporal, o andamento, deve ser adotado nas etapas seguintes de análise da composição, quando o autor promove as formas de compatibilidade entre melodia e letra. Considerando que tanto o programa narrativo como o programa melódico de uma canção visam, em última instância, ao restabelecimento de continuidade entre sujeito e objeto, a seleção extensa do movimento acelerado ou desacelerado já constitui em si um fator significativo que servirá de referência às operações posteriores.

A opção pela melodia veloz ocasiona maior proximidade dos elementos musicais, colocando em evidência os contrastes e as similaridades. Quase não há trajetória a percorrer pois se passa repentinamente de uma etapa a outra. Tais descontinuidades (os contrastes) são ainda reforçadas, na ordem intensa, pelos desdobramentos (mudanças de material musical) e, na ordem extensa, pelas chamadas segundas partes, ambos respondendo pelo progresso sintagmático da obra. Se, a partir da escolha da celeridade, ainda tivéssemos um investimento maciço nos desdobramentos e na criação das outras partes (segunda, terceira, quarta...), certamen- 

p. $131-143,1994 / 1995$.

te presenciaríamos um caso extremo de pacto com o ruído no interior de uma canção. $O$ que se verifica porém, em geral, é a utilização comedida desses recursos para evitar uma excessiva dispersão de sonoridade. A adoção do movimento acelerado provoca imediatamente a atuação dos processos de desaceleração e de recuperação da continuidade. Surgem assim as formas de concentração ou involução que se manifestam, na dimensão intensa, como tematização (similaridades contíguas) e, na dimensão extensa, como refrão. Ambos os recursos visam "refrear" a velocidade do tempo, ressaltando os elos de conjunção melódica. Desse esforço de negação parcial da velocidade nascem as letras desse gênero de canção, quase sempre exaltando a continuidade, ou seja, a perfeita consonância do sujeito com o objeto (o ente amado, a natureza, o país, a música, etc.).

A opção pela melodia lenta revela, de saída, um compromisso com o percurso. Aumentando a distância entre os elementos musicais cresce o interesse pelas etapas intermediárias e pelos detalhes de condução melódica. A oscilação dos tons no campo de tessitura ganha relevo especial uma vez que quanto maior a duração das notas individuais maior o compromisso com a ocupação dos "espaços" agudos e graves e, conseqüentemente, com o perfil traçado pela melodia. Por isso, as descontinuidades que pretendem negar a escolha inicial da desaceleração recaem justamente sobre a evolução vertical dos contornos. Temos assim, no plano intenso, os saltos intervalares e, no plano extenso, as transposições abruptas de registro melódico. Ambos visam romper a expectativa melódica e acelerar o andamento produzindo descontinuidades que se figurativizam como "etapas queimadas" $\mathrm{O}$ aumento de tensão subjetiva provém, nesses casos, da perda de controle sobre as fases do percurso. Em vez de soar como avanço em direção ao objeto, tais descontinuidades soam como desvio de rota e afastamento da meta. Assim como no caso da surpresa, o sujeito precisa refazer as etapas saltadas para recobrar o controle sobre o caminho (e o tempo) ainda por ser percorrido. Daí os recursos de reafirmação do projeto melódico de desaceleração que se manifestam nas formas de gradação, seja no interior de uma escala (os graus imediatos que se processam na ordem intensa), seja na condução de segmentos maiores no sentido ascendente ou descendente. A gradação no eixo vertical corresponde à repetição no eixo horizontal. Ambas atuam em prol das conjunções para assegurar uma continuidade entre sujeito e objeto. Se a busca de continuidade da canção acelerada pode ser reconhecida por um processo geral de concentração, a mesma busca na canção desacelerada pode ser chamada de extensão. Desse esforço de restauração do percurso, muitas vezes fraturado por saltos na progressão melódica, surgem as letras das canções que pertencem à série extensão, geralmente às voltas com os conteúdos passionais devido à perda ou ao distanciamento do objeto (as chamadas canções românticas). ${ }^{11}$

(11) Estudamos minuciosamente esses aspectos de formação da canção nos capítulos III e IV de Semiótica da sanção: melodia e letra. São Paulo, Escuta, 1994, pp. 59-191. 
TATIT, Luiz. A construção do sentido na canção popular. Língua e Literatura, n. 21, p. 131-143, 1994/1995.

\section{Ritmo e sintaxe}

A concentração constitui, assim, a forma extensa de expansão da melodia acelerada. Do mesmo modo, a extensão constitui a forma extensa da melodia desacelerada. Ambos os processos podem ser reconhecidos também por suas microestruturas rítmicas que organizam a dimensão intensa da melodia. Enquanto a aceleração apóia-se num sistema de ataque-acentuação de suas células mínimas (as chamadas figuras rítmicas), a desaceleração decorre do alongamento da duração de seus tons. ${ }^{12} \mathrm{Da}$ variação entre essas duas formas intensas (ataque-acentuação de um lado e tonalização de outro) a teoria musical tradicional retira o conceito de ritmo para suas avaliações e seus ensinamentos técnicos.

Essa perspectiva rítmica pode ser bem aproveitada em nosso modelo, sobretudo numa fase de identificação geral das formas de andamento inicialmente selecionadas e que servirão de fundo para as descrições posteriores. Entretanto, a noção de ritmo só atinge seu verdadeiro estatuto cancional numa dimensão mais ampla de articulação interna da concentração ou da extensão ou, ainda, na própria alternância desses dois processos extensos numa mesma canção (como no caso de Garota de Ipanema, Eu quero um samba, Quereres, etc.). O ritmo nasce assim do encontro das forças coesivas da melodia, aquelas que buscam a continuidade, com as forças dispersivas que provocam rupturas e desvios em sua rota. Para compreendermos tal encaminhamento, nada mais sugestivo que o modelo silábico de Saussure. Uma explosão sonora anuncia imediatamente o mecanismo inverso da implosão. E quanto mais a sonoridade se abre mais iminente é o seu fechamento e vice-versa. ${ }^{13}$ Assim também transcorre o desenvolvimento melódico: quanto maior o investimento na continuidade, mais a descontinuidade se impõe como etapa a ser suplantada. Não há tematização sem desdobramento, não há refrão sem segunda parte e não há gradação de alturas sem a intervenção dos saltos intervalares. A alternância dessas categorias é o grande imperativo rítmico para termos melodia de canção. Constitui uma verdadeira regra de previsibilidade e determinação para o progresso sintagmático da matéria sonora.

As letras de canções exibem um quadro descritivo bem mais conhecido. As persuasões enunciativas do sujeito são sempre secundadas, explícita ou implicitamente, por conteúdos polêmicos cujas descontinuidades valorizam a argumentação do intérprete (algumas canções de Noel Rosa são exemplares nesse sentido: Filosofia, Palpite infeliz, Último desejo, etc.). Um estado de conjunção entre sujeito e objeto quase sempre pressupõe disjunção anterior ou posterior para legitimar a

(12) Cf. L. Tatit, Op. Cit., p. 98.

(13) Cf. F. Saussure, Curso de Lingüistica Geral. São Paulo, Cultrix, 1971, p. 62. 

p. 131-143, 1994/1995.

euforia da situação descrita. A iminência de mudança de um estado para outro, típica de qualquer processo narrativo, institui um ritmo de conteúdo altamente homologável com o ritmo da expressão. Do mesmo modo, as isotopias discursivas -sensoriais, passionais, sociais, conceituais, etc.- são construídas num processo de iteração sêmica que depende das rupturas, das descontinuidades, para se constituir.

Mais que uma sintaxe actancial, podemos detectar, no plano do conteúdo, um ritmo narrativo que também opera com a alternância continuidade / descontinuidade. Mais que um ritmo melódico, podemos identificar, no plano da expressão, uma sintaxe regulando as determinações entre as subcategorias da concentração e da extensão.

\section{Composição e liberdade}

Por mais conflituosos que se apresentem os elementos que compõem um canção, em virtude de um certo excesso de fatores descontínuos, o simples fato de haver leis musicais estabilizando a substância fônica é suficiente para assegurar um gesto inicial em favor da continuidade. Ao conseguir se estabilizar numa canção, a voz que canta interrompe sua atividade enquanto voz que fala e, ao mesmo tempo, instaura-se como extensão material perene de um corpo. Tudo ocorre como se a voz que canta provocasse a descontinuidade dos discursos orais cotidianos e a negasse imediatamente em nome de uma continuidade mais duradoura consubstanciada na composição. Esse processo nos reporta novamente, em escala microscópica, à silabação. A negação da descontinuidade consonantal em função da duração da soante constitui exatamente a definição saussuriana de ponto vocálico.

C. Zilberberg propõe uma surpreendente e interessante relação entre ponto vocálico e ponto de liberdade (ponto libertário).$^{14} \mathrm{O}$ exercício da liberdade decorre, segundo o autor, da negação dos limites deônticos em prol das extensões do desejo. Ao deixar-se aproximar da voz que fala, do modo de produção da linguagem oral, o artista retoma em parte o caráter provisório da fala com o único intuito de negá-lo e, no mesmo ato, reafirmar sua capacidade de reconstruir durações. Criar na tangente da fala é um risco constante que valoriza a perenidade de cada composição.

RÉSUMÉ: A partir des étroites intéractions sémiotique existant entre la chanson et la parole quotidienne, ce travail voudrait contribuer à la reconnaissance d'un lieu théorique où les valeurs essentielles, qui

(14) Cf. Claude Zilberberg "Présence de Wölfflin" In: Nouveaux Actes Sémiotiques. Limoges, Pulim, vol.23-24, p. 68 . 
TATIT, Luiz. A construção do sentido na canção popular. Língua e Literatura, n. 21, p. 131-143, 1994/1995.

imprègnent les mélodies et les paroles de chansons brésiliennes, deviennent compatibles. Plaçant le procès syntagmatique et les catégories temporelles au centre de la réflexion, cet effort se propose de concevoir un fondement méthodologique homogène visant au dévoilement des lois qui engendrent les continuités et les discontinuités réproduites aussi bien dans les paroles que dans les mélodies des chansons.

Mots-clés: continuité, discontinuité, tempo, mélodie, parole. 